\title{
Monitoring and evaluating cataract intervention in India
}

\author{
Hans Limburg, Raj Kumar, D Bachani
}

\begin{abstract}
Aim-To identify indicators to monitor and evaluate the cataract intervention programme in India.

Methods-Available data on blindness due to cataract, demography, staffing levels, and infrastructure available under the programme were reviewed. Four key elements of the programme were identified: the magnitude of blindness due to cataract and the need for surgical services; the available resources; the output, in quantity and in quality, as well as the resource utilisation; and lastly the impact this has on society and the problem of blindness due to cataract. Indicators to quantify these key elements were designed and available data were used to calculate the defined indicators.

Results-At least 2.5 million sight restoring cataract operations will have to be performed annually. Staffing levels and infrastructure resources at present allow for increased output. The effectiveness of cataract services can be increased with better case selection.

Conclusion-The use of these indicators provides an insight into the dynamics of the problem of cataract blindness and its intervention. They facilitate adequate management and evaluation of the efficiency and effectiveness of the intervention programme and may ensure optimal utilisation of the available resources for cataract surgery.

(Br f Ophthalmol 1996;80:951-955)
\end{abstract}

Danish Assistance to the National Programme for Control of Blindness (DANPCB), New Delhi, India

H Limburg

Cataract Blindness

Control Project of the World Bank, India

R Kumar

Directorate General Health Services, Government of India D Bachani

Correspondence to: H Limburg, MD, DANPCB A1/148 Safdarjung Enclave, New Delhi 110 029, India.

Accepted for publication 1 August 1996
In 1976, India was one of the first countries in the world to embark on a national programme for control of blindness. Major emphasis in this programme is given to the expansion of eye care services to combat blindness caused by cataract. India pioneered the concept of eye camps, which brought cataract surgery within reach of people in the remotest areas. Eye care services are provided by the government (free), by non-governmental organisations (free or subsidised), and by the private sector (commercial charges).

The increase in service facilities resulted in a considerable rise in the number of cataract operations: from 0.5 million operations in 1981-2 to 2.2 million in 1994-5. ${ }^{1}$ However, the prevalence of cataract blindness increased even further; from 2.4 million cataract blind people (visual acuity $<3 / 60$ in the better eye, with available correction) in 1974 to 4.3 million in $1986 .^{2}$
The number of cataract operations performed was not sufficient to compensate for the increase in incident cases, as well as the accumulation of a backlog of cataract blindness.

Three questions arose after this experience:

(1) Why has the expansion of eye care services not kept pace with the increase in cataract blindness?

(2) Which indicators were used and why did they not indicate this shortfall in services?

(3) Can other indicators measure more adequately the impact of cataract intervention programmes?

\section{Materials}

POPULATION AT RISK FOR CATARACT BLINDNESS Demographic changes like population growth and aging, together with low utilisation of surgical services, are the main reasons for the worldwide increase in cataract blindness. ${ }^{3}$

In India, the demographic changes have been dramatic over the past 20 years. The population at risk for age related cataract, people of 50 years and older, has increased from 63 million in 1971 to 115 million in 1991 and 125 million in 1995. It is expected to reach 147 million by the year 2000 and be over the 200 million by 2011 (Gupta YP, Population Department, National Institute for Health \& Family Welfare, New Delhi, personal communication).

TARGETS

Every year, the National Programme for Control of Blindness (NPCB) allocates targets for the number of cataract operations to be performed by each state. The state government breaks this up into targets for each district, which may again be divided into targets for each hospital or mobile eye unit. At the end of the year, the number of cataract operations performed by all different units in the government sector, the private sector, and by the nongovernmental organisations (NGOs) are added and compared with the district or state target. Targets are allocated on the basis of previous performance, not on the basis of prevalence of cataract blindness (needs) or capacity of surgical services. No guidelines are issued on which patients are eligible for cataract surgery. Patient details, such as preoperative visual acuity in each eye, first or second eye operated, postoperative visual acuity, were until recently not routinely recorded in a standardised way. The percentage of the target achieved is the main indicator to monitor performance under the NPCB. 
For the year 1994-5, the target for all of India was 2.3 million cataract operations, out of which 2.2 million were performed.

\section{STAFFING}

There are an estimated 8000 ophthalmologists in India, of whom around 5000 are surgically active. The non-operating ophthalmologists are mostly working in places without surgical facilities. On average, there is one ophthalmologist for 112500 people. With a strong concentration of ophthalmologists in the cities, the ratio varies from 1:20000 in the cities to 1:200 000 in most rural districts. ${ }^{4}$ The average number of cataract operations is 440 per eye surgeon per year. The target allocation does not take into account the number of eye surgeons available in a certain area.

\section{FACILITIES}

Although modern day care cataract surgery has made its entry in India, conventional intracapsular cataract extraction is still performed in $80 \%$ of the cases and most eye surgeons prefer to hospitalise their patients for 3-5 days.

The number of designated ophthalmic beds in the government sector is 29000 . A further estimated 31000 beds are with the NGOs and the private sector. ${ }^{5}$ For optimal performance, each surgeon must have enough beds, funds, equipment, and supplies available, which is not always the case. In those places where the number of designated beds is limited, beds from other departments may be used or one may have to rely on improvised arrangements like eye camps for cataract services.

\section{Methods and results}

In order to facilitate adequate monitoring, evaluation and management indicators in cataract intervention programmes should be able to measure the following aspects: (a) the need for cataract intervention in a community; (b) the available resources, staffing levels, infrastructure, and funds to deal with the cataract problem in that community, as well as the capacity of these resources; (c) the annual output, both in quantity and in quality, the resource utilisation, and the effectiveness of cataract intervention services; (d) the impact

Table 1 Indicators for cataract intervention

\begin{tabular}{|c|c|c|c|}
\hline & Indicator & Source & Measure \\
\hline Needs & $\begin{array}{l}\text { Prevalence rate } \\
\text { Prevalence rate 50+ } \\
\text { Incidence }\end{array}$ & $\begin{array}{l}\text { Surveys } \\
\text { Rapid assessment } \\
\text { Cohort study }\end{array}$ & $\begin{array}{l}\% \text { total population } \\
\% \text { population } 50+ \\
\text { New cases/year }\end{array}$ \\
\hline Resources & Capacity & $\begin{array}{l}\text { Assigned } \\
\text { Assigned }\end{array}$ & $\begin{array}{l}\text { Catops/OS/year } \\
\text { Catops/bed/year }\end{array}$ \\
\hline \multirow[t]{3}{*}{ Output } & $\begin{array}{l}\text { Cataract surgical rate } \\
\text { Utilisation }\end{array}$ & $\begin{array}{l}\text { Reports/MIS } \\
\text { Reports/MIS }\end{array}$ & $\begin{array}{l}\text { Catops/mil pop } \\
50+/ \text { year } \\
\text { Catops/OS/year } \\
\text { Catops/bed/year }\end{array}$ \\
\hline & Success rate & Patient records & $\begin{array}{l}\% \text { operated eyes with } \\
\text { sight restored/year }\end{array}$ \\
\hline & Sight restoration rate & Patient records & $\begin{array}{l}\% \text { catops that changed a } \\
\text { blind person to a } \\
\text { sighted person/year }\end{array}$ \\
\hline \multirow[t]{2}{*}{ Impact } & $\begin{array}{l}\text { Cataract surgical } \\
\text { coverage }\end{array}$ & Rapid assessment & $\%$ cases operated \\
\hline & Prevalence rate & Rapid assessment & $\%$ population $50+$ \\
\hline
\end{tabular}

Catops=cataract operations; $O S=$ ophthalmic surgeons; $M I S=$ management information system this output has on the prevalence of blindness in that community-the surgical coverage.

Table 1 gives an overview of the indicators described above. Most indicators can be calculated on the basis of data already available.

Two proposed indicators, the success rate and the sight restoration rate, can be calculated from individual patient records. The other two proposed indicators, prevalence of cataract blindness in people of 50 years and older and the cataract surgical coverage, can be obtained through rapid assessments.

\section{SURGICAL NEEDS}

The need for cataract surgery can be calculated, using the available prevalence data from the WHO-NPCB study of 1986 for India as a whole or for individual states. ${ }^{2}$ The annual incidence of cataract blind people $(\mathrm{VA}<3 / 60)$ is estimated at $\mathbf{2}$ million. ${ }^{1}$ A realistic approach is to calculate the needs against the population at risk for cataract blindness-for example, those people of 50 years and older. To include children would distort the figures on needs for surgery.

The term 'need' has to be used here with caution. It should take into account the definition of cataract blindness, as well as the demand and eligibility for cataract surgery in a particular population. Does the intervention programme focus on removing cataract blindness and restoring functional eyesight, by operating on one eye only, or does it aim on operating on both eyes for optimal visual results? The availability of resources may determine what policy is to be selected.

In India, blindness is defined as visual acuity less than $6 / 60$ in the better eye, with the best available correction. The majority of patients, however, only seek help when their vision falls below $3 / 60$ in the better eye. Most eye surgeons will only operate when the visual acuity is less than $1 / 60$ or $3 / 60$.

In the developed world, patients with cataract and a VA of $6 / 12$ or $6 / 18$, by definition not blind, come for surgery. Therefore, the demand or need for cataract services is much higher than the number of patients, blind due to cataract only.

In this paper, we propose as our goal a maximum reduction in the number of patients blind (VA $<3 / 60)$ as a result of cataract. The needs thus calculated are minimum needs.

In Table 2 the need for cataract surgery in India in 1994 is calculated, both for eyes as well as for people blind due to cataract in the age of 50 years and older. The NPCB estimates the annual incidence of blindness due to cataract to be 2 million people or 4 million eyes at present. To control blindness, at least the number of new cases (annual incidence) has to be covered plus part, say $10 \%$, of the old cases (prevalence $=$ backlog)

In India, with a population of 125 million above 50 years of age, between 2.5 (125 $\times$ $20200)$ and $5.8(125 \times 46400)$ million sight restoring cataract operations have to be performed every year to contain the annual incidence and reduce the backlog. The exact 
Table 2 Needs for cataract surgery: eyes and people

\begin{tabular}{lccc}
\hline Needs & Incidence/mil 50+/year & Prevalencelmil $50+$ & Needs $/$ mil/year \\
\hline Eyes requiring cataract & $4 \mathrm{mil} / 125 \mathrm{mil}=$ & $15.5 \mathrm{mil} / 125 \mathrm{mil}=$ & $32000+12400=$ \\
surgery (VA $<3 / 60)$ & $32000 / \mathrm{mil} /$ year & $124000 / \mathrm{mil}$ & $46400 / \mathrm{mil} 50+/$ year \\
Bilateral cataract blind & $2 \mathrm{mil} / 125 \mathrm{mil}=$ & $5.3 \mathrm{mil} / 125 \mathrm{mil}=$ & $16000+4200=$ \\
people (VA $<3 / 60)$ & $16000 / \mathrm{mil} /$ year & $42000 / \mathrm{mil}$ & $20200 / \mathrm{mil} 50+/$ year
\end{tabular}

Table 3 Resources for cataract surgery and their capacity

\begin{tabular}{lclc}
\hline Resources & Unit/population & Capacity/unit/year & Total capacity/year \\
\hline $\begin{array}{c}\text { Ophthalmic surgeons } \\
\text { (OS) (surgically }\end{array}$ & $5000 / 900 \mathrm{mil}=$ & $700 / \mathrm{OS} / \mathrm{year}$ & $700 \times 5000=$ \\
$\begin{array}{c}\text { active) } \\
\begin{array}{c}\text { Designated ophthalmic } \\
\text { beds }\end{array}\end{array}$ & $1: 180000$ & $3.5 \mathrm{mil}$ cases/year \\
& $60000 / 900 \mathrm{mil}=$ & $40 \mathrm{catops} / \mathrm{bed} / \mathrm{year}$ & $40 \times 60000=$ \\
& $1: 15000$ & $2.4 \mathrm{mil} \mathrm{cases} / \mathrm{year}$ \\
\hline
\end{tabular}

figure depends upon the prevailing policy on eligibility for cataract surgery-surgery in one eye to restore functional eyesight or in both eyes for optimal visual rehabilitation.

Similarly, the needs for sight restoring cataract surgery in any state or district can be calculated. On average, $13 \%$ of the population in India are older than 50.

\section{RESOURCES}

Information on staffing resources, infrastructure, funds and supplies for cataract intervention, is available with the national programme. To determine the optimal capacity of available resources and to measure whether that capacity is utilised, norms have been set on the number of cataract operations per eye surgeon per year, the number of cataract operations per ophthalmic bed per year, requirements for drugs, diagnostic and surgical equipment, spectacles, etc. In India, the NPCB has fixed the norms at 700 cataract operations per eye surgeon per year and 40 operations per designated eye bed per year.

The capacity for cataract surgery in a district or a state should be adequate to cover the needs. When capacity is less, the first and most important task of the state programme officer (NPCB) will be to arrange sufficient staffing levels and infrastructure.

Table 3 shows that, if the target is set to 700 cataract operations (catops) per year per ophthalmic surgeon, the existing number of eye surgeons in India allows for an increase in cataract surgery, but it is limited to cover future needs.

The number of 60000 designated eye beds seems sufficient, considering that at present around $50 \%$ of the cataract operations are performed in camp settings. The utilisation of designated eye beds is, on average, $30-40 \%{ }^{6}$ The introduction of modern techniques will increase institutionalised surgery and, at the same time, reduce the period of hospitalisation. Surgical eye camps will continue to be required, especially in rural areas, while institutional capacity is being expanded. Shortage of designated eye beds is not likely to become a constraint.

\section{OUTPUT}

The annual output of the cataract intervention programme in India is measured by the number of cataract operations only. Without a denominator, this is a poor indicator. Foster ${ }^{7}$ uses the total population as a denominator to calculate the cataract surgical rate (CSR). The population of 50 years and older may even be more accurate to compare with the needs. Table 4 gives an impression of the capacity to cover the needs for cataract surgery. Similar calculations can be made for any state or district.

Measuring the number of cataract operations per year per eye surgeon gives a good idea about utilisation of staffing capacity. Similarly, the number of operations per eye bed per year measures the utilisation of bed capacity.

Comparing the output of 2.2 million cataract operations in 1994-5 with the needs and the capacity of the resources gives the following process indicators (Table 4).

Not all 2.2 million cataract operations change a blind person into a sighted person as will be illustrated later. Therefore, the actual output in terms of sight restoring operations is not sufficient to cover the needs.

With 440 operations per eye surgeon in $1994-5$, the staffing utilisation is $63 \%$. Assuming $50 \%$ of the cataract operations are performed in eye camps, the bed utilisation is $45 \%$.

When the two indicators, catops per million population $(50+)$ per year and catops per eye surgeon per year, are compared with the needs and the assigned optimal output of staff respectively, they may provide important clues on the operational aspects of the cataract surgical services in a particular district or state (Table 5).

Output should also be monitored on qualitative aspects. The indicator commonly used is the success rate: the percentage of operations that resulted in restoration of sight in the operated eye in a particular year. Agreement should be reached on the definition of this 'sight restoration'. Does it mean a visual acuity better than $3 / 60$ in the operated eye, better than $6 / 60$, or better than $6 / 18$ ?

$$
S R=\frac{E(\text { pre })-E(\text { post })}{\text { total catops } / \text { year }} \times 100
$$

where $S R=$ Success rate in a particular year $\mathrm{E}(\mathrm{pre})=$ preoperative visual acuity in the operated eye

$\mathrm{E}($ post $)=$ postoperative visual acuity in the operated eye

Table 4 Output of cataract surgery: capacity, actual, and needs

\begin{tabular}{|c|c|c|c|c|c|c|}
\hline \multirow[b]{2}{*}{ Year } & \multicolumn{2}{|l|}{ Catops/mil 50+/year } & \multicolumn{2}{|l|}{ Catops/OS/year } & \multicolumn{2}{|l|}{ Catops/bed/year } \\
\hline & Actual & Needs & Actual & Capacity & Actual & Capacity \\
\hline $94-5$ & $\begin{array}{r}2200000 / 125 \mathrm{mil}= \\
17600 / \mathrm{mil} 50+/ \mathrm{yr}\end{array}$ & $\begin{array}{l}20200 / \mathrm{mil} 50+/ \text { year to } \\
46400 / \mathrm{mil} 50+/ \text { year }\end{array}$ & $\begin{array}{c}2200000 / 5000= \\
440 / \text { OS/year }\end{array}$ & 700/OS/year & $\begin{array}{r}1100000 / 60000= \\
18 / \mathrm{bed} / \text { year }\end{array}$ & 40/bed/year \\
\hline
\end{tabular}


Table 5 Indicators and operational aspects of cataract surgical services

\begin{tabular}{lll}
\hline Indicator & Value & Possible conclusions \\
\hline $\begin{array}{l}\text { Catops/mil pop 50+ } \\
\text { Catops/OS }\end{array}$ & $\begin{array}{l}\text { Low } \\
\text { Low }\end{array}$ & $\begin{array}{l}\text { Poor case finding; constraints in infrastructure, } \\
\text { supplies or transport; rejection of cases; poor } \\
\text { credibility of services }\end{array}$ \\
$\begin{array}{lll}\text { Catops/mil pop 50+ } \\
\text { Catops/OS }\end{array}$ & $\begin{array}{l}\text { Low } \\
\text { High }\end{array}$ & $\begin{array}{l}\text { Shortage of ophthalmic surgeons; facilities and } \\
\text { supplies seem adequate }\end{array}$ \\
$\begin{array}{ll}\text { Catops/mil pop 50+ } \\
\text { Catops/OS }\end{array}$ & $\begin{array}{l}\text { High } \\
\text { Low }\end{array}$ & $\begin{array}{l}\text { Too many ophthalmic surgeons for this particular } \\
\text { population; case finding adequate }\end{array}$ \\
Catops/mil pop 50+ & High & Efficient services; well balanced \\
Catops/OS & High & \\
\hline
\end{tabular}

Individual patient records in a standardised format with pre- and postoperative visual acuity have been introduced recently in the Indian programme to obtain data to determine the success rate. Various articles indicate that the success rate, defined as postoperative visual acuity equal to or better than $6 / 18$ with best correction, varies between 85 and $95 \% .^{89}$ Initial data from the newly introduced formats suggest similar results. Most patients, operated in the conventional way, are provided with a standard spherical correction of +10 dioptres. With individual adjusted correction, the success rate would have been considerably higher.

Using individual patients records, it is also possible to measure the proportion of cataract operations that resulted in restoring eyesight in bilaterally cataract blind people, who, subsequently, can be removed from the prevalence. It is a measure of effectiveness of the cataract intervention programme in a particular year.

$$
\mathrm{SRR}=\frac{\mathrm{P}(\text { pre })-\mathrm{P}(\text { post })}{\text { total catops } / \text { year }} \times 100
$$

where $S R R=$ sight restoration rate/year $\mathrm{P}($ pre $)=$ people blind (preop) $/$ year $\mathrm{P}($ post $)=$ people blind (postop)/year

The sight restoration rate is determined by the success rate as well as by the selection criteria for cataract surgery. Removing the cataract in the first eye of a bilaterally blind person will restore eyesight in around $90 \%$ of cases in India. Operating on the second eye in the same patient may improve the quality of vision, but does not reduce blindness any further. When only bilaterally blind people are selected for surgery and operated in only one eye, the sight restoration rate becomes equal to the success rate, $90 \%$.
In developing countries where resources are limited, priority should be to remove the disability caused by blindness in as many people as possible.

As with the success rate, sight restoration has to be defined in terms of visual acuity.

The sight restoration rate of two surgical units $^{1011}$ is given in Table 6 . In this case, sight restoration was defined as a person blind preoperatively (VA less than $3 / 60$ in the better eye) and not blind (VA $>3 / 60$ and $>6 / 60$ respectively) postoperatively.

It is remarkable that the sight restoration rate is so low. To some extent, this can be attributed to the suboptimal success rate. The main cause, however, is the fact that only $33-43 \%$ of the patients were bilaterally blind, the other $57-67 \%$ being unilaterally blind persons. This illustrates clearly that case selection is the major factor determining the effectiveness of the cataract intervention programme.

IMPACT

So far, the impact of a cataract intervention programme, to which extent it has reduced cataract blindness, has not been measured routinely.

After several years of intervention activities, a new prevalence survey should be undertaken. This would indicate the change in prevalence compared with the baseline data, obtained at the start of the intervention. But blindness surveys are lengthy and expensive exercises and often are repeated only after a decade or more. We have developed a rapid assessment methodology to measure the prevalence of cataract blindness in persons of 50 years and older which requires a smaller sample and is less costly.

A rapid assessment can also provide a second indicator, which we call the cataract surgical coverage. This indicator measures the coverage of the intervention: what proportion of the problem of cataract blindness has been covered by services in the form of cataract surgery, irrespective of the outcome. A comparison can be drawn with the immunisation programme: the number of vaccinations given is not so important, but the percentage of children covered is.

This coverage indicator can be used for cataract blind eyes, as well as people bilaterally blind from cataract. It gives a good impression on the availability and accessibility of cataract surgical services over the past period to date.

Table 6 Sight restoration rate in two units

\begin{tabular}{|c|c|c|c|c|c|c|}
\hline \multirow[b]{2}{*}{$\begin{array}{l}\text { Visual } \\
\text { acuity }\end{array}$} & \multicolumn{3}{|c|}{ Preoperative visual acuity } & \multicolumn{3}{|c|}{ Postoperative visual acuity } \\
\hline & $\begin{array}{l}\text { Eye camps } \\
\text { ('95) }\end{array}$ & $\begin{array}{l}\text { Ludhiana } \\
\text { ('84'93) }\end{array}$ & $\begin{array}{l}\text { Ludhiana } \\
\text { ('94) }\end{array}$ & $\begin{array}{l}\text { Eye camps } \\
\text { ('95) }\end{array}$ & $\begin{array}{l}\text { Ludhiana } \\
\text { ('84'93) }\end{array}$ & $\begin{array}{l}\text { Ludhiana } \\
\text { ('94) }\end{array}$ \\
\hline $\begin{array}{l}6 / 6-6 / 18 \\
<6 / 18-6 / 60 \\
<6 / 60-3 / 60 \\
<3 / 60-P L \\
\text { Total } \\
\text { Sight restora } \\
\text { Sight restora }\end{array}$ & $\begin{array}{l}57 \\
28 \\
41 \\
93 \\
219 \\
\text { rate (pre-op } \\
\text { rate (pre-op }\end{array}$ & $\begin{array}{l}4429 \\
5971 \\
2815 \\
10106 \\
23321 \\
3 / 60 \text {-posto } \\
3 / 60 \text { - posto }\end{array}$ & $\begin{array}{l}618 \\
1226 \\
509 \\
1183 \\
3536 \\
\end{array}$ & $\begin{array}{l}145 \\
67 \\
7 \\
0 \\
219 \\
43 \% \\
39 \%\end{array}$ & $\begin{array}{l}8665 \\
12633 \\
935 \\
1088 \\
23321 \\
39 \% \\
35 \%\end{array}$ & \begin{tabular}{l|}
1530 \\
1813 \\
79 \\
114 \\
3536 \\
$30 \%$ \\
$28 \%$
\end{tabular} \\
\hline
\end{tabular}


Table 7 Aphakic coverage in three districts

\begin{tabular}{llll}
\hline District & $\begin{array}{l}\text { Aphakic } \\
\text { coverage } \\
\text { (eyes) }\end{array}$ & $\begin{array}{l}\text { Prevalence } \\
\text { cataract blind } \\
\text { eyes 50+ }\end{array}$ & $\begin{array}{l}\text { Prevalence cataract } \\
\text { blind people 50+ }\end{array}$ \\
\hline Tumkur & $33 \%$ & $10 \%$ & $3.5 \%$ \\
Salem & $46 \%$ & $10 \%$ & $4.0 \%$ \\
Purnea & $22 \%$ & $18 \%$ & $8.4 \%$ \\
\hline
\end{tabular}

Cataract surgical coverage (people) $=$ (people with 1 or 2 aphakic eyes)/ (cataract blind people + aphakic people) Cataract surgical coverage (eyes) $=$

(no of aphakic eyes)/(cataract blind eyes + aphakic eyes)

For this indicator, aphakia and pseudophakia should be considered to be identical.

Calculating the cataract surgical coverage for eyes and people separately will illustrate the influence of case selection as in the sight restoration rate. Theoretically and ideally, the intervention programme should first attempt to remove the disability of blindness in all people by operating on one eye first. This would give a coverage in people of $100 \%$, a coverage in eyes of $50 \%$.

Three rapid assessments have been conducted in three districts in India on a trial basis. The results are indicated in Table 7 . The prevalence in people of 50 years and older varied from $3.5 \%$ in Tumkur to $8.4 \%$ in Purnea. The cataract surgical coverage indicates a better availability and utilisation of services in Salem, although the prevalence of cataract blindness among the people at risk is higher than in Tumkur.

\section{Discussion}

India has made impressive strides in building up staffing levels and infrastructure for the control of cataract blindness during the past 6 years. This has resulted in an increase in cataract surgery from 1.1 million operations in 1989 to 2.2 million in 1994. However, demographic changes have outdone most of these achievements. The 2.2 million cataract surgeries performed in 1994-5 are not sufficient to cover the requirements of 2.5 to 5.8 million sight restoring operations. Subsequently, cataract blindness in India has increased further during the past decade.

At present, eye surgeons and designated eye beds are not utilised optimally. An increase to 3.5 million cataract operations per year should be possible with the available staff and resources. Conditions are that enough cases are coming forward through increased demand and case finding and that surgeons have all the essential facilities and supplies to do their work. To meet future demands, ophthalmic staffing levels need to be expanded and encouraged to establish themselves outside the major cities.
The success rate of conventional cataract surgery is reported to be, on average, $90 \%$, both in camps as well in hospitals. With the introduction of a standardised cataract surgical record throughout India, more and better data on the quality of cataract surgery are expected.

Calculation of the sight restoration rate indicated that 'cataract operation done' is not the same as 'sight restored'. A sight restoration rate of $28-43 \%$ indicates that, at present, the limited resources for cataract surgery are not focused on prevention of blindness but more on achieving targets.

With better case selection and active case finding of bilaterally cataract blind people, the effectiveness can increase considerably with more blind people having their sight restored with the same effort.

A cataract surgical coverage (eyes) varying from $22 \%$ to $46 \%$ shows that a considerable load of cataract blindness is yet to be covered.

By using these indicators, a detailed insight and a clear understanding of the dynamics of cataract blindness can be obtained. The same indicators are also the essential variables to be entered into mathematical models through which future disease prevalence and the likely impact of different intervention strategies can be estimated. ${ }^{12}$

This will facilitate effective and efficient management of cataract blindness intervention programmes.

The authors are grateful to Dr Richard Daniel and Dr Arin Chatterjee of the Christian Medical College and Hospital, Ludhiana, India, for permission to use their mobile unit data. The authors also thank Allen Foster, senior lecturer, International Centre for Eye Health, Institute of Ophthalmology, national Centre for Eye Health, Institute of Ophthalmology, Department of Ophthalmology, Academisch Ziekenhuis, Department of Ophthalmology, Academisch
Utrecht, Netherlands, for their valuable comments.

1 Information from Ophthalmology Section, Directorate General of Health Services, Ministry of Health and Family Welfare, New Dehli: Government of India.

2 Madan Mohan. Survey of Blindness-India, summary and results. Dr Rajendra Prasad Centre for Ophthalmic Sciences, New Delhi: All India Institute for Medical Sciences, 1989.

3 Foster A, Johnson GJ. Blindness in the developing world. $\mathrm{Br}$ f Ophthalmol 1993;77:398-9.

4 Kumar R. Ophthalmic manpower in India: need for a serious review. Int Ophthalmol 1993;17:269-75.

5 Directory of Hospitals in India, 1988, Central Bureau of Health Intelligence, Directorate General of Health Services, Ministry of Health and Family Welfare, Government of India.

6 Operations Research Group. The National Programme for Control of Blindness-A Situational Analysis, study report, 1990.

7 Foster A. A simple method for evaluating surgical cataract services in prevention of blindness programmes. Community Eye Health 1992;10:2-5.

8 Reidy A, Mehra V, Minassian D, Mahashabde S. Outcome of cataract surgery in central India: a longitudinal follow up study. Br $¥$ Ophthalmol 1991;75:102-5.

9 Hennig A, Shrestha SP, Foster A. Results and evaluation of high volume intracapsular cataract surgery in Nepal. Acta Ophthalmol 1992;70:402-6.

10 Eye camp records, Tumkur, Hassan and Chitradurga District, Karnataka and Sangli District, Maharashtra, India.

11 Daniel R. Annual Report 1993, Mobile Eye Services, Christian Medical College and Hospital, Ludhiana, Punjab, India.

12 Limburg H, Kumar R, Bachani D. Forecasting cataract blindness-and planning how to combat it. World Health Forum 1996;17:15-20. 